\title{
Correction to: Nurtured in Nature: a Pilot Randomized Controlled Trial to Increase Time in Greenspace among Urban-Dwelling Postpartum Women
}

\author{
Eugenia C. South • Kathleen Lee • Kehinde Oyekanmi • David G. Buckler • Max Jordan Nguemeni Tiako • \\ Tyler Martin • Sara L. Kornfield • Sindhu Srinivas
}

Published online: 19 July 2021

(C) The New York Academy of Medicine 2021

\section{Correction to: J Urban Health.}

https://doi.org/10.1007/s11524-021-00544-z

There was an error in the title of this article as originally published.

The word "Pregnant" in the title should have read "Postpartum".

The online version of the original article can be found at https://doi.org/10.1007/s11524-021-00544-Z

E. C. South $(\bowtie) \cdot$ K. Lee $\cdot$ K. Oyekanmi $\cdot$ D. G. Buckler Department of Emergency Medicine, University of Pennsylvania, Blockley Hall, Room 408, 423 Guardian Drive, Philadelphia, PA 19104, USA

e-mail: eugenia.south@pennmedicine.upenn.edu

E. C. South · K. Oyekanmi - D. G. Buckler · M. J. N. Tiako Urban Health Lab, University of Pennsylvania, Philadelphia, PA, USA

\section{J. N. Tiako}

Yale School of Medicine, New Haven, CT, USA

T. Martin

Center for Healthcare Innovation, University of Pennsylvania,

Philadelphia, PA, USA

\section{S. L. Kornfield}

Department of Psychiatry, University of Pennsylvania, Philadelphia, PA, USA

\section{S. Srinivas}

Department of Obstetrics and Gynecology, University of Pennsylvania, Philadelphia, PA, USA
Hence, the correct article title is:

Nurtured in Nature: a Pilot Randomized Controlled Trial to Increase Time in Greenspace among UrbanDwelling Postpartum Women

The original article has been corrected.

Publisher's Note Springer Nature remains neutral with regard to jurisdictional claims in published maps and institutional affiliations. 